PAPER

\title{
HIV and the right not to know
}

\author{
Jonathan Youngs, ${ }^{1}$ Joshua Simmonds ${ }^{2}$
}

${ }^{1}$ Core Medical Training, St George's Hospital, London, UK ${ }^{2}$ Accident and Emergency, Wexham Park Hospital, Frimley Health NHS Foundation Trust, Berkshire, UK

\section{Correspondence to} Dr Jonathan Youngs, Core Medical Training, St George's Hospital, Blackshaw Road, Tooting, London SW17 0QT, UK; youngs.jonathan@gmail.com

Received 13 June 2015 Revised 28 August 2015 Accepted 27 October 2015 Published Online First 24 November 2015

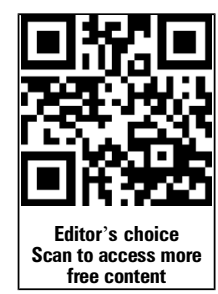

\section{Linked}

- http://dx.doi.org/10.1136/ medethics-2015-103210

- http://dx.doi.org/10.1136/ medethics-2015-103211

- http://dx.doi.org/10.1136/ medethics-2015-103212

- http://dx.doi.org/10.1136/ medethics-2015-103213

- http://dx.doi.org/10.1136/

medethics-2015-103289

CrossMark

To cite: Youngs J, Simmonds J. J Med Ethics 2016:42:95-99.

\section{ABSTRACT}

It is a tenet of the prevailing ethic in medicine that competent adults have the 'right to know' information necessary to make informed decisions about their healthcare. Whether there is a 'right not to know' unwanted information is more hotly debated. When deciding whether or not to override a competent adult's desire not to know his/her HIV result, a desire to respect patient autonomy can be seen to pull in both directions. We thus conclude that there is not a very strong presumption on the side of non-disclosure but rather the adult's interest in not knowing must be weighed against the potential harms and benefits of disclosure for both the individual and others. This does not, however, negate the fact that patients retain a right to refuse an HIV test and this is so even where issues of bodily integrity are not at stake. This implies that explicit consent should still be sought for HIV testing, at least where there is some possibility that the patient may refuse, or want more information, if given the chance.

\section{INTRODUCTION}

It is a tenet of the prevailing ethic in medicine that competent adults have the 'right to know' information necessary to make informed decisions about their healthcare. ${ }^{1}$ Whether there is a 'right not to know' unwanted information is more hotly debated. In this paper, we argue that while there is no 'right not to know' one's HIV result, there remains a 'right to refuse' an HIV test. We shall refer to 'the three facts' about HIV throughout our discussion:

1. HIV is treatable: with timely anti-retroviral therapy, people living with HIV can now expect a normal life expectancy. ${ }^{2}$

2. Delaying diagnosis increases mortality: individuals diagnosed late with HIV are ten times more likely to die in the first year after diagnosis than those diagnosed earlier. ${ }^{3}$

3. Diagnosing HIV benefits others: diagnosing HIV enables modification of sexual behaviour ${ }^{4}$ and lowering viral load with medication further reduces transmission. ${ }^{2}$ Diagnosis enables partner notification and contact tracing so that others can themselves benefit from early diagnosis and treatment.

\section{THE RIGHT TO REFUSE AN HIV TEST}

Let us start by considering:

Test refusal, Peter is recovering from Cryptococcal meningitis. His consultant, Dr. Smith, offers an HIV test (Cryptococcal meningitis is an AIDS-defining condition). Peter refuses, and continues to do so despite Dr. Smith exploring Peter's reasons to ensure he holds no "incorrect beliefs about the virus or the consequences of testing". 5

The three facts are strong reasons to believe an HIV test is in Peter's best interests. A negative result would presumably be a relief to him, and a reactive result is the gateway to potentially lifesaving treatment. ${ }^{6}$ Others may also benefit because once diagnosed with HIV, Peter may be less likely to pass on the infection, and partner notification and contact tracing can take place. Despite these potential benefits to both Peter and others, Dr Smith may hold that it is wrong to perform an HIV test against Peter's refusal. He might believe that respecting Peter's autonomy requires that he be allowed to decide for himself whether to undergo an HIV test. Let us state this claim as:

Claim- $A$, competent adults have the right to refuse an HIV test.

It should be clear that what is being asserted here is a moral right, not a legal one. ${ }^{7}$ Whether it is illegal for Dr Smith to perform an HIV test against Peter's refusal depends on what jurisdiction he practices in and whether he has already taken a blood sample. ${ }^{8}$ We are concerned with whether it is immoral to perform the HIV test.

'Rights language' can obscure a debate rather than illuminate it. 910 We thus attempt to 'unpack' such usage. We can restate Claim- $A$ as:

Claim- $A$, there is a very strong presumption that it is morally wrong to override a competent adult's refusal of an HIV test.

It might be objected that what is meant by a right to refuse (RTR) is stated too weakly here. When some people talk of a right to refuse, they mean:

Absolute-RTR, it is always morally wrong to override a competent adult's refusal of medical intervention.

$\mathrm{Or}$

Strong-RTR, it is always morally wrong to override a competent adult's refusal of medical intervention unless doing so might prevent serious harm to others.

Those who believe public health grounds could make it morally permissible to force someone to provide a throat swab in the event of a deadly influenza pandemic do not subscribe to Absolute-RTR. Strong-RTR is more attractive, but it still maintains it can never be morally permissible to override a competent adult's refusal for paternalistic reasons. This is close to the position of English law, under which it is a crime of battery to override a 
competent adult's refusal of a caesarean section even where refusal will result in death of the mother and her unborn child. ${ }^{11}$ But the fact that adults may be treated under the Mental Health Act, ${ }^{12}$ against a competent refusal, suggests that even English law does not endorse Strong-RTR.

We do not attempt to refute Absolute-RTR or Strong-RTR, but simply want to clarify our use of 'right' in Claim-A (which we hold) and Claim- $B$ (which we deny below) asserts a prima facie claim. ${ }^{7}$ Under what circumstances it might be morally permissible to overturn this prima facie position shall not be discussed.

\section{THE RIGHT TO REFUSE AN HIV RESULT}

Does it follow from a right to refuse an HIV test that patients have a right not to know an HIV result? Let us state this claim as:

Claim-B, competent adults have the right not to know their HIV result.

\section{$\mathrm{Or}$}

Claim- $B$, there is a very strong presumption that it is morally wrong to override a competent adult's desire not to know their HIV result.

To make clear the distinction between Claim-A and Claim-B, consider:

Result refusal, Peter is recovering from Cryptococcal meningitis. Whilst unconscious during a prolonged stay on the intensive care unit his consultant, Dr. Smith, performed an HIV test in his best interests. Now awake, Dr. Smith explains the situation, and asks Peter if he would like to know his result. Peter refuses.

Dr Smith would never have ordered the test against Peter's refusal (Claim- $A$ ), but now he knows the result, he is unsure whether Peter has a right not to know it (Claim-B).

It might be objected that by informing Peter of his HIV test and tentatively offering a result, Dr Smith has effectively told Peter that he has HIV. This might be so, but a policy of openness and honesty is clearly in accord with professional values. ${ }^{13}$

It might also be observed that Peter must have some reason for refusing his HIV result and this should be handled sensitively. This is undoubtedly so. It may be that Peter is in denial, that he is scared or that after being diagnosed with meningitis he is simply not ready for more bad news. Despite advances in treatment, a diagnosis of HIV still carries huge social implications and stigma lingers. But let us assume that despite Dr Smith's attempts to address these concerns Peter maintains his desire not to know.

Peter's clear desire not to know his HIV result might suggest that telling him is unlikely to do any good. But to argue this is already to enter into a harm-benefit analysis of what Dr Smith should do, rather than defend Claim-B. This harm-benefit analysis shall be returned to.

Some circumstances might allow for patients to receive the benefits of treatment while maintaining their desire not to know but it is difficult to see how this could work in the case of HIV. If Dr Smith recommended that Peter start taking antiretroviral medications and his partner have an HIV test, then one imagines Peter might feel his desire not to know had been thwarted. These objections aside we now turn to whether Claim- $B$ is true.

\section{THE RIGHT NOT TO KNOW}

The Convention on Human Rights and Biomedicine (CHRB) states:
10(2): Everyone is entitled to know any information collected about his or her health. However, the wishes of individuals not to be so informed shall be observed. ${ }^{14}$

\section{Autonomy and privacy entail a right not to know}

The meaning and value of 'autonomy' is hotly contested, ${ }^{15}$ but it is often said that respecting autonomy requires (but is not necessarily limited to) allowing patients to make decisions for themselves whether or not you think this will harm them. ${ }^{9}$ Conversely, paternalism involves making decisions on behalf of patients because you think this will benefit them, whether or not they agree. ${ }^{7}$

Andorno argues that respecting autonomy therefore entails that a patient's decision not to know a certain piece of information should be respected. ${ }^{16}$ To override someone's desire not to know is, on this view, to paternalistically frustrate their autonomous decision for their own good, and this is never permissible. For Andorno, the right not to know may only be overridden in the interests of others:

Claim- $B^{A}$, it is always morally wrong to override a competent adult's desire not to know unless disclosure might prevent serious harm to others.

Jonathan Herring and Charles Foster share Andorno's view that respecting patients' desire not to know promotes autonomy. ${ }^{17}$ They provide the following example:

Dr. Fearful, has had blood tests performed that indicate whether or not he has a predisposition to dementia. He pleads not to be told the results.

It is notable that in Herring and Foster's examples, respecting the patient's desire not to know leads to an outcome that the doctor could agree was in their best interests. This makes it unclear whether justification for respecting the desire not to know lies in respecting patient autonomy (as they claim) or paternalism. A better test is to ask whether a patient's desire not to know should be respected where this goes against their best interests. Herring and Foster themselves answer this question in the negative: 'If the condition is serious and treatment is available, it will be very unlikely that disclosure will not be justified'. They also believe that the right not to know may be overturned in the interest of others. Their position appears to be:

Claim- $B^{H \leftrightarrow F}$, there is a very strong presumption that it is morally wrong to override a competent adult's desire not to know unless disclosure might prevent serious harm to the individual or others.

Explanatory notes suggest that the CHRB also hold Claim- $B^{H \mho F}$ :
70:[I]t may be of vital importance for patients to know certain facts about their health, even though they have expressed the wish not to know them...It could also be appropriate to inform an individual that he or she has a particular condition when there is a risk not only to that person but also to others. ${ }^{18}$

Laurie denies a right not to know can be grounded in autonomy, but holds that individuals are entitled to protect their psychological integrity from being invaded by unwanted information. ${ }^{19}$ According to this argument, we all enjoy a private sphere-a psychological separateness from other people -and we have a legitimate interest in shielding that sphere from information that would violate and degrade it. ${ }^{20}$ Laurie is quick to point out that this confers an 'interest' not to know rather than a 'right', and advises disclosure may be warranted to offer treatment for a severe illness or where the interests of others are at stake. He thus too seems to endorse Claim- $B^{H \mho r F}$. 
As the three facts make clear, disclosure of HIV may prevent serious harm to both the individual and others. This suggests that neither Andorno, Herring, Foster, Laurie nor the CHRB would defend Claim-B. Of course, the three facts are heavily time and place sensitive. In a country without access to HIV treatment, Claim-B would be easier to defend. ${ }^{21}$

\section{Autonomy and privacy do not entail a right not to know}

John Harris denies that there is a right not to know. ${ }^{22} \mathrm{He}$ understands 'right' in this context as an entitlement that trumps competing claims and must be granted overriding respect. He is therefore arguing against something close to Claim- $B^{A}$.

Harris agrees with Andorno that respecting autonomy involves allowing patients to make decisions for themselves, but contends that this does not imply that any decision must be respected-it matters whether or not the decision was autonomous. Decisions are less autonomous when ill-informed, because it is our ability to make choices based on the information that we deem important to pursue the things that we value that makes them our own. Where our decisions are made on faulty information, we may find that they take us farther from those things we value rather than closer. This leads Harris to conclude that promoting autonomy usually requires that information be provided, not withheld. Ost borrows an example from Mill to illustrate this point: ${ }^{23}$

Bridge, a man is about to cross a bridge that we know is structurally unsound such that any attempt to cross it will likely result in injury.

Ost argues that respect for the man's autonomy demands that we ensure he is aware of the danger, but we must then allow him to proceed if that is his choice. If the man were to stop our warning short stating, 'I do not want to know', Ost argues that allowing him to cross the bridge 'unwarned' does not promote his autonomy-on knowing the risk, he may have chosen autonomously not to cross. Similarly, Peter, on knowing that he has HIV, may autonomously consent to treatment and partner notification. This means withholding that knowledge because he asks you to may frustrate his autonomous decision-making rather than promote it.

While Harris denies a 'right' not to know grounded in 'autonomy', he defends an 'interest' not to know, grounded in 'liberty'. This interest would, however, be relatively weak, and could be overridden where others have competing liberty interests or an interest in avoiding harm for instance. Harris' arguments also suggest that Dr Smith's interest in not shouldering the responsibility of Peter's HIV diagnosis might also override Peter's liberty interest in not knowing it. We might state Harris' position as:

Claim- $B^{H}$, there is no presumption that it is morally wrong to override a competent adult's desire not to know. The adult's interest in not knowing must be weighed against the potential harms and benefits of disclosure for both the individual and others.

\section{Claim- $B$ is false}

Informing Peter of his HIV result would override a decision of his, but it is at least unclear whether this violates his autonomy. Not telling Peter denies him the chance to make informed decisions about his health and so a desire to promote autonomy can be seen to pull in both directions. Even if there is generally a very strong presumption that it is morally wrong to override a competent adult's desire not to know (whether on autonomy, liberty or privacy grounds), this is not so in the case of a reactive HIV result. This is because disclosure might prevent serious harm to the individual or others.

Even if there is no 'right not to know' one's HIV result, it does not necessarily follow that Dr Smith should tell Peter he has HIV. Dr Smith must weigh Peter's interest in not knowing against the potential harms and benefits of disclosure for both him and others. ${ }^{22}$ This will involve consideration of how Peter will take the news and whether he is likely to want treatment for HIV. How disclosure might affect the doctor-patient relationship and Peter's ongoing care for meningitis will also be relevant. It is impossible to say in abstract what would be the right thing to do but we suggest the three facts weigh heavily in favour of telling Peter his result.

\section{CAN CLAIM-A HOLD TRUE IF CLAIM-B IS FALSE?}

\section{Consider:}

Just-in-time, Peter is recovering from Cryptococcal meningitis. Whilst unconscious during a prolonged stay on the intensive care unit his consultant, Dr. Smith, requested an HIV test in his best interests. Now awake, Dr. Smith explains the situation, and asks Peter if he consents to the test going ahead. Peter refuses. Dr. Smith rings the laboratory: the test is currently in progress.

Claim-A (which we defend) suggests that Dr Smith should cancel Peter's test. This is because allowing it to run is to knowingly override his refusal, and Claim- $A$ asserts there is a very strong presumption that this is morally wrong. That we deny Claim-B suggests that if the test does go ahead (for whatever reason) and Peter refuses his result, there is no moral presumption that he should not be told. This ethical position is tenable because there are good reasons to hold that it is morally worse to override refusal of an HIV test than an HIV result. We suggest, however, that respect for autonomy is not one of them.

As described above, people who believe that respect for autonomy creates a general 'right not to know' (Claim- $B$ and Claim- $B^{H \odot F}$ ) can hold that Claim-B is false because disclosing an HIV result might prevent serious harm to the individual or others. These people might then continue to defend Claim-A on autonomy grounds by observing that testing someone for HIV against a refusal does not prevent such serious harm. This is because the three facts are more distant before an HIV test than where a reactive result is known. The difficulty with this approach is that it means Claim-A would become weaker the stronger Dr Smith's suspicion of HIV. We find this implication unacceptable because it implies that groups at greater risk of HIV (such as 'men who have sex with men' and 'black-Africans'3 ) have less right to refuse an HIV test. This same difficulty arises when trying to defend Claim-A on liberty grounds. Furthermore, a patient might sometimes present with a condition or blood results that are essentially diagnostic for HIV/AIDS. In this situation, it would become increasingly untenable to continue to defend Claim-A on autonomy grounds and yet still hold that autonomy grounds are insufficient to defend Claim-B. In these circumstances, the patient's right to refuse an HIV test would become increasingly meaninglesstheir doctor would, in fact, be closer to the position of Dr Smith in Result refusal. Since Claim-B is false, we suggest that the patient's interest in not knowing that he almost certainly has HIV would have to be weighed against the potential harms and benefits of disclosure for both the individual and others.

Other people believe that respect for autonomy does not create a general 'right not to know' $\left(\right.$ Claim- $\left.B^{H}\right)$ and so can similarly deny Claim-B. These people will find it hard to then 
defend Claim-A on autonomy grounds. If informing Peter of a reactive result in Result refusal can be seen to promote his autonomous decision-making, so too can testing him against his refusal in Just-in-time. This is because testing, like disclosure, enables Peter to make important informed decisions about his health. It might be objected that overriding someone's refusal to be tested for HIV is a greater violation of autonomy than overriding someone's desire not to know a result. But removed here from the issue of bodily integrity (the blood has already been taken) it is unclear why this is so-in both cases, the decision of whether or not to learn one's HIV status is stolen from the individual.

Defending Claim-A on autonomy grounds is problematic, but we present three arguments that provide good reasons to support it.

First:

Consequences argument, endorsing a rule whereby doctors may test someone for HIV when they have refused will have dire consequences. $^{24}$

Once Peter learns that Dr Smith allowed his HIV test to continue, he will probably be outraged and likely lose trust in his medical team. ${ }^{8}$ If such a practice became commonplace, it could shatter the reputation of the medical profession more generally. This would have a harmful impact on the public's likelihood to seek and follow medical advice.

Second:

O'Neill argument, testing someone for HIV when they have refused amounts to coercion and deception. ${ }^{15}$

Dr Smith sought Peter's consent for an HIV test and he refused. To perform the test anyway on blood already taken is to trick Peter into undergoing a test that he does not agree to. This can be said to be wrong on both consequentialist and deontological grounds. Deontological, because to coerce or deceive Peter is to disrespect him as an end in himself whose say over decisions affecting him, and his blood, ought to be given

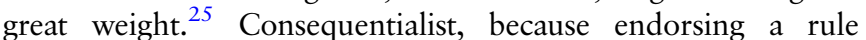
whereby doctors coerce and deceive their patients will have dire consequences. In this sense, the second argument might be subsumed within the first.

Manavi and Welsby have suggested that 'explicit' consent for HIV testing is an antiquated relic of HIV exceptionalism. ${ }^{26}$ They argue it should be possible to request an HIV test among a set of routine blood tests consented to in 'general' terms. If we imagine Manavi and Welsby's approach became the norm then testing someone for HIV, without explicitly giving them the chance to refuse, would not necessarily involve coercion or deception. Under such a system, a doctor might innocently assume that his patient implicitly consented to a possible HIV test when they consented to routine blood tests being taken. This might suggest that if testing for HIV under the Manavi and Welsby approach is wrong, it must be wrong for some reason other than the O'Neill argument.

It is, however, still possible for coercion and deception to flourish under the Manavi and Welsby approach. A doctor might take blood after obtaining 'general' consent, and then test for HIV even where he knows there is a reasonable possibility the patient would have refused the blood tests had HIV been explicitly mentioned. Alternatively, a doctor might take blood and then test for HIV even where he knows the patient has, in fact, requested that their blood not be tested for HIV. Such practices would involve coercion and deception. We suggest this makes them more wrong, than where the doctor innocently assumes that his patient implicitly consented to a possible HIV test. These examples imply that 'explicit' consent should still be sought for HIV testing, at least where there is some possibility that the patient may refuse, or want more information, if given the chance.

Third:

Privacy argument, testing someone for HIV when they have refused amounts to an invasion of privacy.

When someone consents to an HIV test, they implicitly grant their doctor access to the result. Where consent has been withdrawn, or never given, Dr Smith has no more claim to Peter's HIV result than a stranger. Allowing the test to run amounts to Dr Smith invading his own patient's privacy and making 'known' information that Peter wishes to be kept 'unknown'. It might be objected that Dr Smith derives authority to do so from his position as Peter's doctor. But since Peter is a competent adult, Dr Smith is only his doctor as long as he consents; Dr Smith's claim to information about Peter ceases once that consent is withdrawn. This argument would not, admittedly, prohibit a court order from authorising the HIV test on public health grounds. ${ }^{8}$ This could be an instance where the 'very strong presumption' of Claim-A is overturned.

This argument too can be defended on both consequentialist and deontological grounds. Deontological, because invading Peter's privacy can be said to be wrong in itself by disrespecting him as a person. Defended this way the privacy argument is close to, and faces the same challenges as, arguments from autonomy and liberty. The privacy argument can also be defended on consequentialist grounds: endorsing a rule whereby doctors may invade their patients' privacy will have dire consequences. In this sense, the third argument, like the second, might also be subsumed within the first.

It is possible to imagine scenarios in which people might be tested for HIV, against a refusal, without invading their privacy:

HIV Screening Programme, The state implements a new HIV screening programme. All blood samples in its possession are tested for HIV. Results are then sent securely and confidentially to those tested. This is an automated programme whereby results are not revealed to anyone other than the patient concerned. Neither those conducting the testing nor the patient's doctors can access the result without the patient's permission or, in some circumstances, a court order.

Under this imaginary HIV Screening Programme, a patient might be tested for HIV against a refusal, but this would not involve an invasion of privacy. If the HIV Screening Programme is wrong, it must be wrong for some reason other than the Privacy argument. But this does not detract from this argument. We suggest that testing Peter for HIV against his refusal under the HIV Screening Programme intuitively feels less wrong than were Dr Smith to test Peter against his refusal in Just-in-time. The fact that the HIV Screening Programme does not involve an invasion of his privacy might explain this difference.

Evaluating whether the HIV Screening Programme is ethical lies outside the scope of this essay, but we shall briefly consider the probable consequences of such a programme. In its favour, we have argued that Claim- $B$ is false, and informing patients that they have HIV under such a programme could produce great benefit for both them and others (the three facts). Against the programme, we have argued that Claim- $A$ is true. Furthermore, endorsing a rule whereby the state may test samples in its possession for diseases when the public have refused will probably have dire consequences. Such a practice 
could shatter the reputation of the government and the health service in particular. This could have a harmful impact on the public's likelihood to seek and follow medical advice.

\section{CONCLUSION}

When deciding whether or not to override a competent adult's desire not to know their HIV result, a desire to respect patient autonomy can be seen to pull in both directions. We thus conclude that there is not a very strong presumption on the side of non-disclosure but rather the adult's interest in not knowing must be weighed against the potential harms and benefits of disclosure for both the individual and others. This does not, however, negate the fact that patients retain a right to refuse an HIV test and this is so even where issues of bodily integrity are not at stake. This implies that 'explicit' consent should still be sought for HIV testing, at least where there is some possibility that the patient may refuse, or want more information, if given the chance.

Contributors JY conceived of the idea for the paper and wrote the first draft. JS critiqued and provided feedback on the various drafts and helped shape the final version of the paper.

Competing interests None declared.

Provenance and peer review Not commissioned; externally peer reviewed.

\section{REFERENCES}

1 Montgomery v Lanarkshire Health Board (Scotland)[2015] UKSC 11

2 Rayment M, Asboe M, Sullivan AK. HIV testing and management of newly diagnosed HIV. BMJ 2014;349:94275.

3 Public Health England. HIV in the United Kingdom: 2014 Report. https://www.gov. uk/government/uploads/system/uploads/attachment_data/file/377194/2014_PHE_ HIV_annual_report_19_11_2014.pdf (accessed 1 Feb 2015).

4 Fox J, White PJ, Macdonald N, et al. Reductions in HIV transmission risk behaviour following diagnosis of primary HIV infection: a cohort of high-risk men who have sex with men. HIV Med 2009;10:432-8.

5 British HIV Association, British Association of Sexual Health and HIV, British Infection Society. UK National Guidelines for HIV Testing, 2008.

6 British HIV Association. British HIV Association guidelines for the treatment of HIV-1-positive adults with antiretroviral therapy 2012. HIV Med 2014;15:1-85 www.bhiva.org/documents/guidelines/treatment/2012/hiv1029_2.pdf (accessed 7 Apr 2015)

7 Glover J. Chapter 5: autonomy and rights. In: Causing death and saving lives. Penguin Books, 1977:74-85.

8 Cowan E, Macklin R. Unconsented HIV testing in cases of occupational exposure: ethics, law, and policy. Acad Emerg Med 2012:19:1181-7.

9 Harris J. Chapter 10: respect for persons I. In: The value of life: an introduction to medical ethics. Routledge 1985:192-213.

10 Singer P. Chapter 4: what's wrong with killing? In: Practical ethics. 2nd edn. Cambridge University Press, 1993:83-109.

11 St George's Healthcare NHS Trust v S; R v Collins and others, ex parte S[1998] 3 All ER 673.

12 Mental Health Act 1983. Section 58(3)(b) www.legislation.gov.uk/ukpga/1983/20/ section/58 (accessed 1 May 2015).

13 Department of health. The handbook to the NHS constitution. 2013:0-143 www. nhs.uk/choiceintheNHS/Rightsandpledges/NHSConstitution/Documents/2013/ handbook-to-the-nhs-constitution.pdf

14 Council of Europe. Convention for the Protection of Human Rights and Dignity of the Human Being with regard to the Application of Biology and Medicine: Convention on Human Rights and Biomedicine, 1997 www.conventions.coe.int Treaty/en/Treaties/Html/164.htm (accessed 7 Mar 2015).

15 O'Neill 0. Some limits of informed consent. J Med Ethics 2003;29:4-7.

16 Andorno R. The right not to know: an autonomy based approach. J Med Ethics 2004;30:435-40.

17 Herring J, Foster C. "Please Don't Tell Me". The Right Not to know. Camb Q Healthc Ethics 2012:21:20-9.

18 Council of Europe. Convention for the protection of human rights and dignity of the human being with regard to the application of biology and medicine: convention on human rights and biomedicine. Explanatory Report. 1997 www.conventions.coe.int/ Treaty/en/Reports/Html/164.htm (accessed 9 Mar 2015).

19 Laurie G. Commentary: a response to Andorno. J Med Ethics 2004; 30:439-40.

20 Laurie G. Recognizing the right not to know: conceptual, professional, and legal implications. J Law Med Ethics 2014;42:53-63.

21 Temmerman M, Ndinya-Achola J, Ambani J, et al. The right not to know HIV-test results. Lancet 1995:15;345(8955):969-70.

22 Harris J, Keywood K. Ignorance, information and autonomy. Theor Med Bioeth 2001;22:415-36

23 Ost DE. The 'right' not to know. J Med Philos 1984;9:301-12.

24 Parker M. Consent to HIV testing and consequentialism in health care ethics. HEC Forum 2004;16:45-52.

25 O'Neill O. Between consenting adults. Philos Public Aff 1985;14:252-77.

26 Manavi K, Welsby PD. HIV testing: Should no longer be accorded any special status. BMJ 2005:330:492-3. 